\title{
Groundwater vulnerability assessment in the vicinity of Ramtha wastewater treatment plant, North Jordan
}

\author{
Muheeb Awawdeh • Mutewekil Obeidat • \\ Ghusun Zaiter
}

Received: 26 December 2013/Accepted: 22 April 2014/Published online: 8 July 2014

(C) The Author(s) 2014. This article is published with open access at Springerlink.com

\begin{abstract}
The main aim of this study was to evaluate the vulnerability of groundwater to contamination in the vicinity of Ramtha wastewater treatment plant using a modified DRASTIC method in a GIS environment. A groundwater pollution potential map was prepared using modified DRASTIC method by adding lineaments and land use/land cover parameters. The values of the modified DRASTIC index were classified into three categories: low, moderate and high. About $36.5 \%$ of the study area is occupied by the high vulnerability class, $56.5 \%$ is occupied by the moderate vulnerability class and $9 \%$ is occupied by the low vulnerability class. Chemical analysis of the water samples collected from wells distributed in the study area and tapping Umm Rijam aquifer indicated that the nitrate concentration ranges from 20 to $193 \mathrm{mg} / \mathrm{L}$ with an average $65.5 \mathrm{mg} / \mathrm{L}$. Nitrate exceeded the permissible limits of WHO and Jordanian standards in 69 and $54 \%$ of the $\mathrm{NO}_{3}{ }^{-}$samples, respectively. The modified DRASTIC model was validated using nitrate concentration. Results showed a good match between nitrate concentrations level and the groundwater vulnerability classes.
\end{abstract}

Keywords Groundwater vulnerability · Ramtha wastewater treatment plant · DRASTIC · Geographic Information System · Nitrate

\footnotetext{
M. Awawdeh $(\bowtie) \cdot$ G. Zaiter

Department of Earth and Environmental Sciences, Yarmouk

University, Irbid, Jordan

e-mail: awawdeh@yu.edu.jo

M. Obeidat

Faculty of Science and Arts, Jordan University of Science and Technology, Irbid 22110, Jordan
}

\section{Introduction}

Jordan has very limited natural resources; it is ranked among the five most water-poor countries in the world (United Nations 2006). Current water availability in Jordan amounts to about 150 cubic meters per capita per year, but it is predicted to be about 91 cubic meters per capita per year by the year 2025, if no action has been made to meet the increasing need for water (Hadadin et al. 2010).

Water quality in Jordan has deteriorated due to various sources of pollution, and over-abstraction resulting in salinization. Over-abstraction of groundwater for irrigation has reduced the water table by $5 \mathrm{~m}$ in some aquifers and tripled salinity, and unregulated $\mathrm{N}$-fertilizer application has increased nitrates in water supplies (Wardam 2004). Industrial discharges are improperly treated or untreated, which introduce toxicity into water resources (Mohsen 2007). It is found that about $70 \%$ of spring water has biological contamination and surface water has high fecal coliform counts from non-point pollution sources, including point sources (wastewater treatment plants) operating over capacity (Wardam 2004). In recent years, nitrate has become a major source of groundwater pollution in Jordan (Margane et al. 1999). Therefore, groundwater pollution prevention and control are particularly critical. Hence, the research on groundwater vulnerability is essential to ensure the quality of groundwater and realize the sustainability of groundwater resources.

Nowadays, groundwater vulnerability assessment has become a useful tool for groundwater pollution prevention. Groundwater vulnerability mapping can indicate regions which are more vulnerable to contamination in the planning stage of socio-economic activities (Fritch et al. 2000; Huan et al. 2012). Vulnerability maps of aquifers are an important tool for the groundwater management and 
protection (Zwahlen 2004). Groundwater vulnerability maps provide useful information to protect groundwater resources and to evaluate the potential for water quality improvement with changes in agricultural practices and land use applications (Babiker et al. 2005; Burkart and Feher 1996; Connell and Daele 2003; Rupert 2001).

Vrba and Zaporozec (1994) distinguished intrinsic (or natural) vulnerability from specific (or integrated) vulnerability; the first term defined solely as a function of hydrogeological factors and the latter term defined by the potential impacts of specific land uses and contaminants. In other words, specific vulnerability integrates the contamination risk placed upon aquifers by human activities (Stigter et al. 2006). The intrinsic vulnerability of groundwater to contaminants takes into account the geological, pedological, hydrological and hydrogeological characteristics of an area (Vrba and Zaporozec 1994). Several methods have been developed to evaluate groundwater vulnerability, and choosing an appropriate one depends on many factors such as scale of the study area, data availability, and desired results (Al-Hanbali and Kondoh 2008). The most widely used method of vulnerability evaluation is DRASTIC model (Aller et al. 1987) due to its ease to use, minimum data requirement, and clear explanation of groundwater vulnerability.

The objectives of this study are (1) to assess the groundwater vulnerability to contamination in the study area using a modified DRASTIC method, and (2) to validate the groundwater vulnerability mapping using nitrate measurements.

\section{Study area}

The study area is a sub-basin of the Yarmouk River watershed, north Jordan (Fig. 1). Ramtha Wastewater Treatment Plant (RWWTP), located in the study area, was established in 1986 to serve the city of Ramtha. The plant is receiving wastewater from a population of about 70,000 people. Stabilization ponds were used in the treatment process. The activated sludge treatment process was used after upgrading the plant in 2003. Evaluation of several options for reuse of the reclaimed wastewater showed that agricultural use was the most suitable alternative. The agricultural land irrigated with the reclaimed wastewater is about $1 \mathrm{~km}^{2}$, located around the plant. The climate of the study area has transitive climatic characteristics between the most humid zone of the country and the desert. The summer is hot and dry with mean daily temperature ranging from 19 to $31^{\circ} \mathrm{C}$. The mean annual minimum and maximum temperatures are 10.7 and $23.7^{\circ} \mathrm{C}$, respectively. Rainfall occurs mainly from November to March, with mean annual rainfall (1976-2002) at Ramtha rainfall station is $213.8 \mathrm{~mm}$. Geologically, the study area consists of Oligocene Basalt (Ba), Wadi Shallala Chalk Formation (B5), which consists of chert and limestone of early Middle-early Late Eocene age, Umm Rijam Chert Limestone Formation (B4), which consists of chert and limestone of Paleocene age, and Amman Silicified Limestone (B2) of campanian age (Natural Resources Authority 1997) (Fig. 2). The subsurface geology comprises Mesozoic
Fig. 1 Location map of the study area

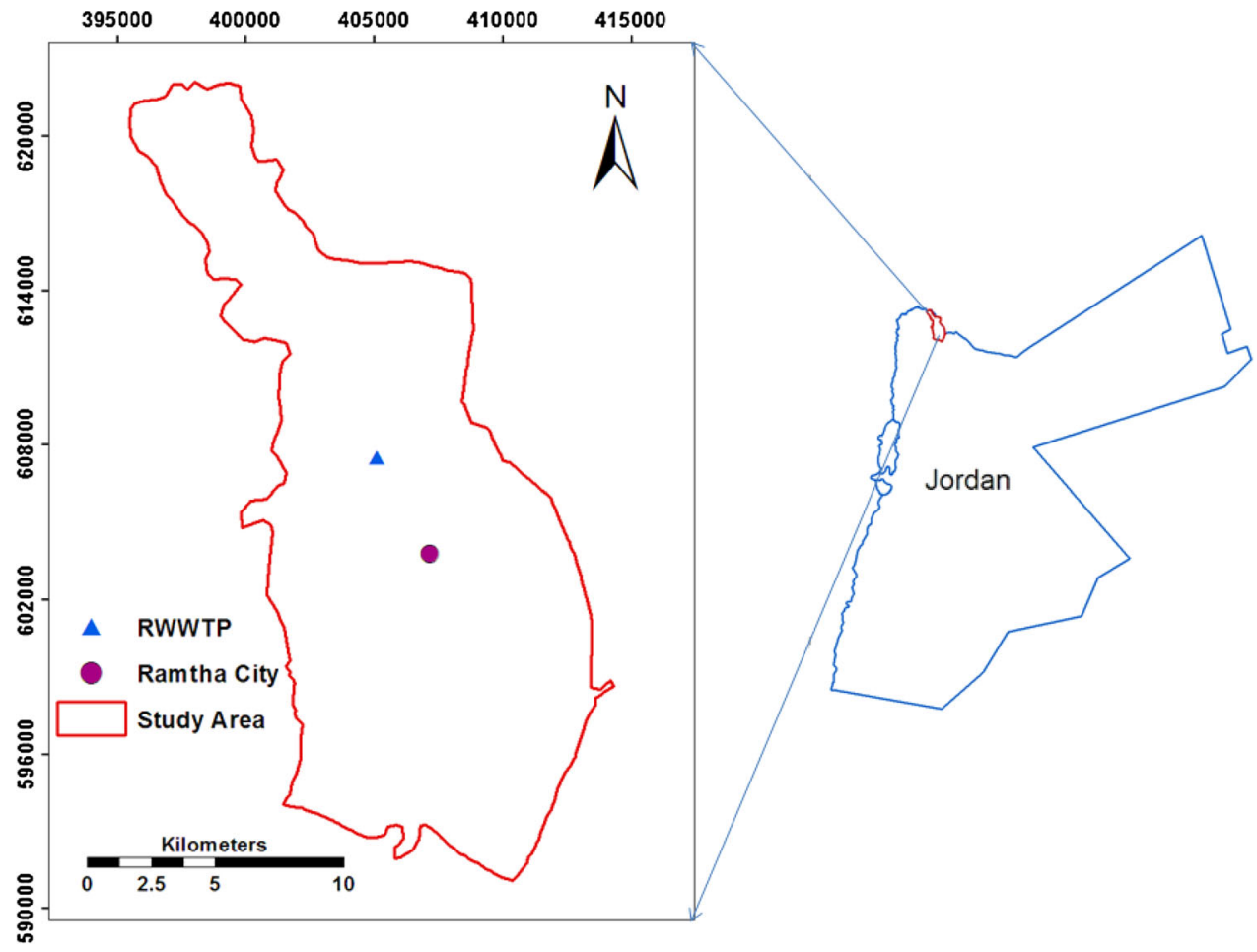




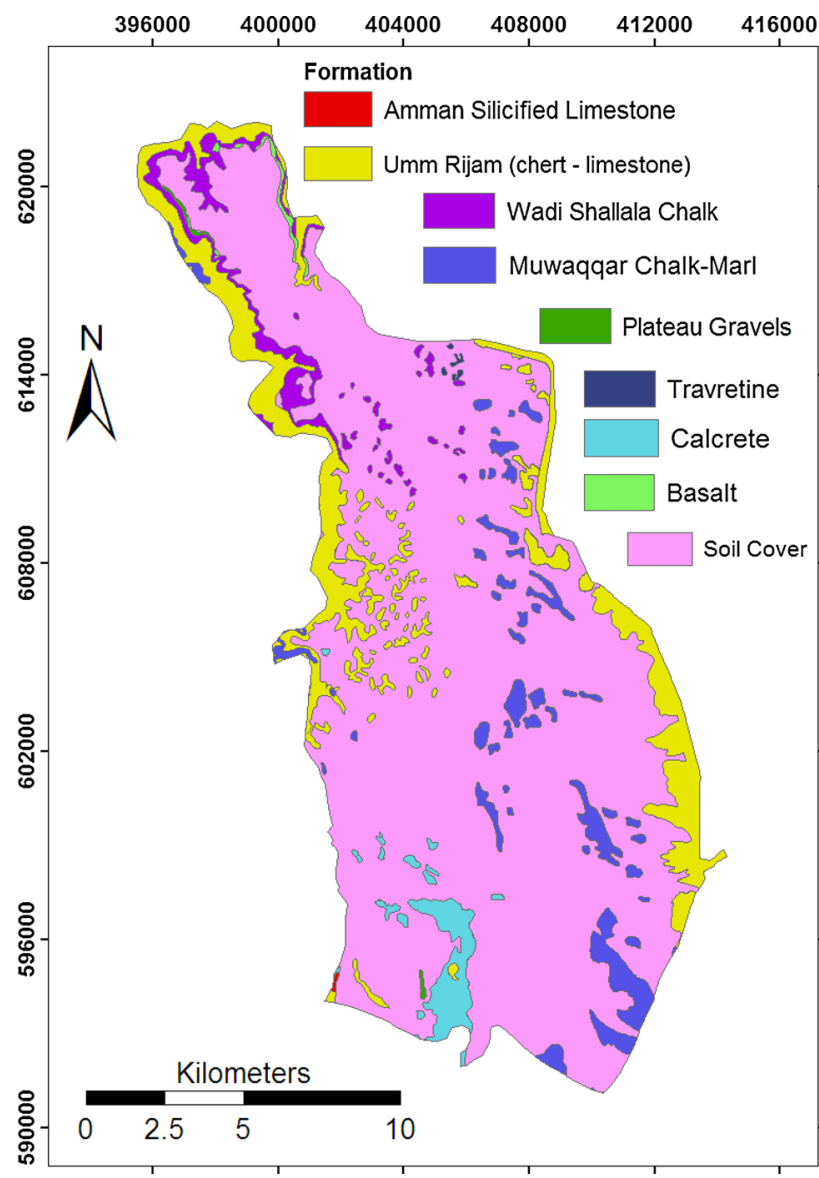

Fig. 2 Geology map of the study area

rocks that consist of Wadi Es Sir Limestone Formation (A7) of Turonian age and Muwaqqar Chalk Marl Formation (B3) of Maastrichtian age. From a hydrogeological point of view, the study area comprises two main aquifer systems: the Wadi Shallala/Umm Rijam (B5/B4). The second aquifer system consists of the Amman/Wadi Es Sir formations (B2/A7).

\section{Materials and methods}

Groundwater vulnerability assessment

DRASTIC is one of the most widely used models to assess groundwater vulnerability (Awawdeh and Jaradat 2010; Evans and Mayers 1990; Fritch et al. 2000; Knox et al. 1993; Nawafleh et al. 2011; Piscopo 2001; Rundquist et al. 1991; Secunda et al. 1998). In this model, spatial datasets on Depth to groundwater, Net Recharge, Aquifer media, Soil media, Topography, Impact of the vadose zone and the hydraulic Conductivity of the aquifer are combined (Navulur and Engel 1998). It is a numerical rating scheme,
Table 1 The DRASTIC model parameters

\begin{tabular}{|c|c|c|}
\hline Factor & Description & Weight \\
\hline Depth to water & $\begin{array}{l}\text { Defined as the depth from the ground } \\
\text { surface to the water level; deeper water } \\
\text { level is less vulnerable to contamination }\end{array}$ & 5 \\
\hline $\begin{array}{l}\text { Impact of } \\
\text { vadose zone }\end{array}$ & $\begin{array}{l}\text { Represents the unsaturated zone, which } \\
\text { attenuates the potential contamination of } \\
\text { the aquifer }\end{array}$ & 5 \\
\hline Net recharge & $\begin{array}{l}\text { It is the amount of the water that penetrates } \\
\text { the ground surface and reaches the water } \\
\text { table. Recharge water transports the } \\
\text { contaminants to the aquifer }\end{array}$ & 4 \\
\hline $\begin{array}{l}\text { Hydraulic } \\
\text { conductivity }\end{array}$ & $\begin{array}{l}\text { Defines the ability of the aquifer to transport } \\
\text { water, which determines the flow rate of } \\
\text { contaminants }\end{array}$ & 3 \\
\hline Aquifer media & $\begin{array}{l}\text { Refers to the saturated zone material } \\
\text { properties, which controls the pollutant } \\
\text { attenuation processes }\end{array}$ & 3 \\
\hline Soil media & $\begin{array}{l}\text { The unconsolidated or loose covering that } \\
\text { covers the surface of the earth. It controls } \\
\text { the amount of water infiltration }\end{array}$ & 2 \\
\hline Topography & $\begin{array}{l}\text { It is the slope of the land surface, which } \\
\text { determines the amount of surface runoff; } \\
\text { hence the amount of water percolation to } \\
\text { the saturated zone }\end{array}$ & 1 \\
\hline
\end{tabular}

which was developed by the US Environmental Protection Agency (Aller et al. 1987; US EPA 1994). Determination of the DRASTIC index involves multiplying each factor weight by its point rating (Table 1) and summing the total (Knox et al. 1993). Rating (r) reflects the significance of classes which vary from 1 to 10 within each parameter and Weight $(w)$ designates the importance for the parameter, and ranges between 1 and 5 (Fortin et al. 1997; Fritch et al. 2000; Knox et al. 1993).

In this study, two additional parameters were added to DRASTIC model to map the groundwater vulnerability in the study area more accurately: lineaments density and land use/land cover. Both parameters were assigned a weight value equal to 5 , and the modified DRASTIC index is calculated using the following equation:

$$
\begin{aligned}
& \text { Modified DRASTIC Index (MDI) }=D_{r} \times D_{w}+R_{r} \times R_{w} \\
& +A_{r} \times A_{w}+S_{r} \times S_{w}+T_{r} \times T_{w}+I_{r} \times I_{w}+C_{r} \times C_{w} \\
& \quad+L_{r} \times L_{w}+\mathrm{LULC}_{r} \times \mathrm{LULC}_{w}
\end{aligned}
$$

where $D$ depth to groundwater, $R$ recharge rate (net), $A$ aquifer media, $S$ soil media, $T$ topography (slope), I impact of the vadose zone, $C$ conductivity (hydraulic) of the aquifer, $L$ lineaments density, LULC: land use/land cover.

ArcGIS 10 was used to process the datasets and to create the groundwater vulnerability map by overlaying the available data. 
Sensitivity analysis

Sensitivity analysis (SA) is a significant component of any modeling project as it allows evaluation of the accuracy of the result (Baker 1992).Two sensitivity tests were performed; the map removal sensitivity analyses introduced by Lodwick et al. (1990) and the single-parameter sensitivity analysis introduced by Napolitano and Fabbri (1996). The map removal sensitivity analysis was performed to evaluate whether it was necessary to use all the parameters incorporated in the DRASTIC model (Hasiniaina et al. 2010). Lodwick et al. (1990) define a map removal sensitivity measure that represents the sensitivity associated with removing one parameter each time; it was computed using the equation:

$S_{\mathrm{x}}=$ Absolute $\left(\left(V_{\mathrm{f}} / N\right)-\left(V_{\mathrm{x}} / n\right)\right)$

where $S_{\mathrm{x}}$ sensitivity associated with the removal of one parameter, $V_{\mathrm{f}}$ final model, $V_{\mathrm{x}}$ model excluding parameter, $N$ number of parameter used in final model, $n$ : number of parameter used in model without one parameter.

To assess the magnitude of variation created by removal of one parameter, the variation index $V$ was calculated using the equation:

$V=\left(V_{\mathrm{f}}-V_{\mathrm{x}}\right) / V_{\mathrm{f}} \times 100$

where $V$ variation index of the removal parameter, $V_{\mathrm{f}}$ final model, $V_{\mathrm{x}}$ model excluding parameter.

The single-parameter sensitivity measure was developed to evaluate the impact of each of the DRASTIC parameters on the vulnerability index. It has been made to compare the effective or real weight of each input parameter in each polygon with the theoretical weight assigned by the analytical model (Babiker et al. 2005). It was computed using the equation:

$W=\left(W_{\mathrm{r}} \times W_{\mathrm{w}}\right) / V_{\mathrm{f}} \times 100$

where $W$ is the effective weight, $W_{\mathrm{r}}$ and $W_{\mathrm{w}}$ are the rating value and weight of each parameter, $V_{\mathrm{f}}$ is the final model.

\section{Model validation}

There are several validation methods of groundwater vulnerability mapping including correlation coefficient of the groundwater vulnerability and the actual pollution occurrence, the corresponding relationship between the extreme nitrate concentration and the vulnerability classes, analysis of variance of F statistic (Lake 2003) and level difference (Stigter et al. 2006). In most cases, correlation of vulnerability results with actual pollution occurrence is used (McLay et al. 2001; Rupert 2001), which was adopted for this study. The validation process is demonstrated by taking nitrate as the typical pollutant.
Nitrate $\left(\mathrm{NO}_{3}{ }^{-}\right)$is among the most important indicators of water resources contamination. Nitrate comes into water supplies through several sources such as septic systems (MacQuarrie et al. 2001), and fertilizers applied in agricultural fields, which contribute most to groundwater pollution (Baker 1992; Hubbard and Sheridan 1994; Postma et al. 1991). Urban development can also increase nitrate concentrations in groundwater (Ford and Tellam 1994; Lerner et al. 1999) through landfills, septic tanks and cesspools, domestic and industrial effluents, leaky sewage system and gasoline stations (Navarro and Carbonell 2007; Seiler 2005; Wakida and Lerner 2005).

Groundwater samples were collected during September and October 2011 from 12 wells (Fig. 3) tapping the B5/B4 aquifer. The methods described by APHA (1998) were followed during field and laboratory works. In addition, historical records of the hydrochemistry of groundwater were retrieved from Water Authority of Jordan (WAJ) archive from 1971 to 2008 . At the time of sampling, basic information such as well location, depth and land use surrounding the wells was collected. Water samples were collected in clean polyethylene bottles washed previously with sampled water and tested in the field for the following

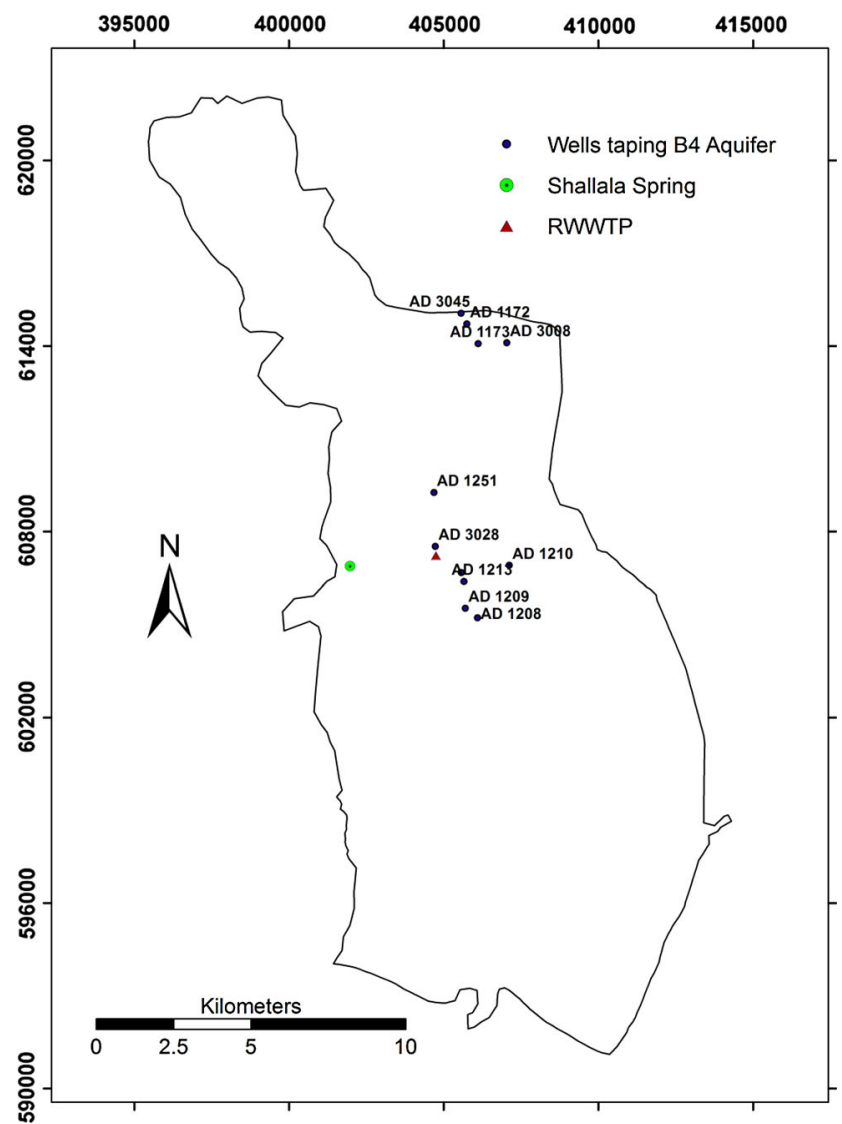

Fig. 3 Sampled groundwater wells in the study area 

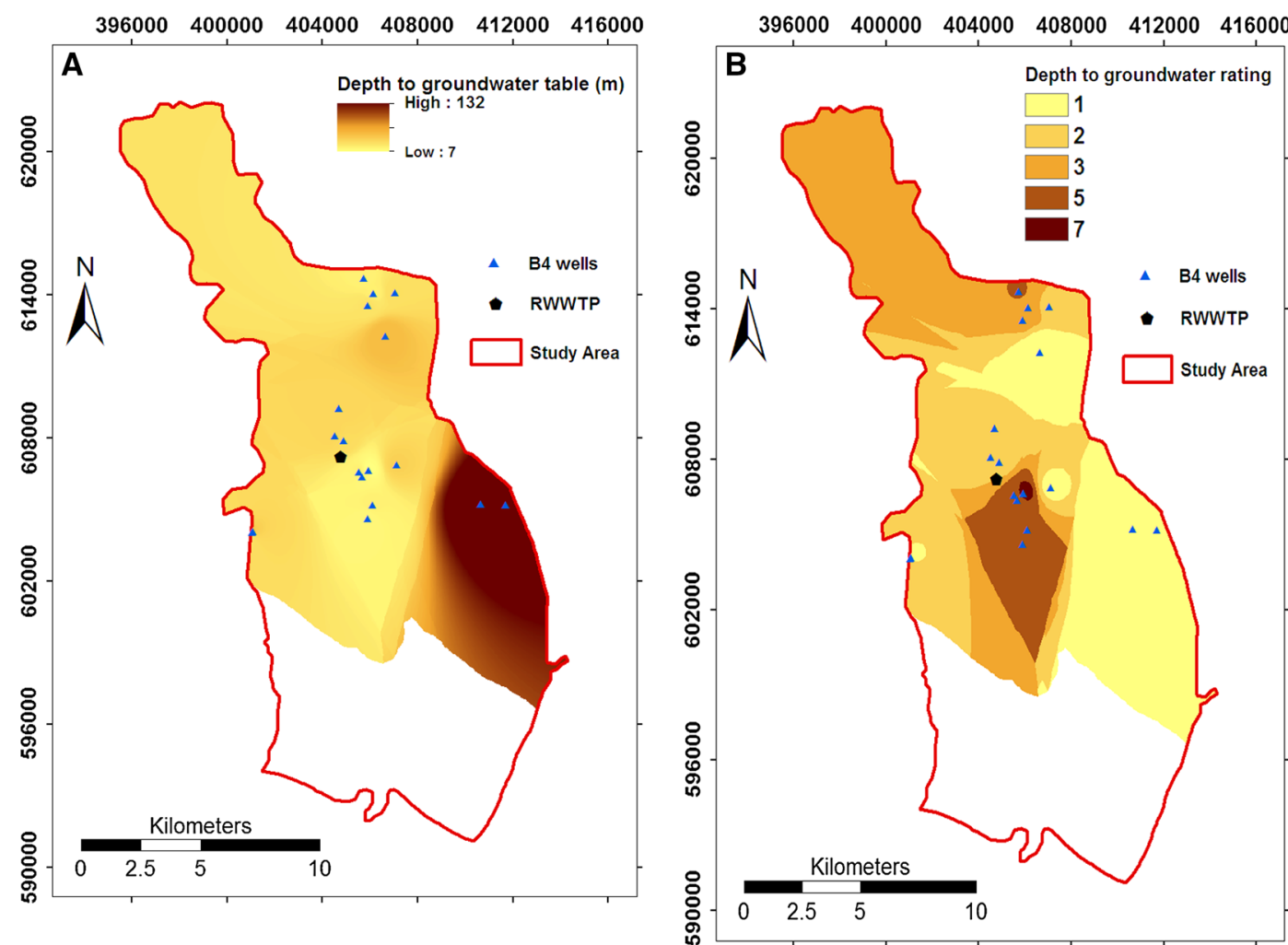

Fig. 4 Map of depth to groundwater contour map (a) and depth to groundwater rating (b) in the study area
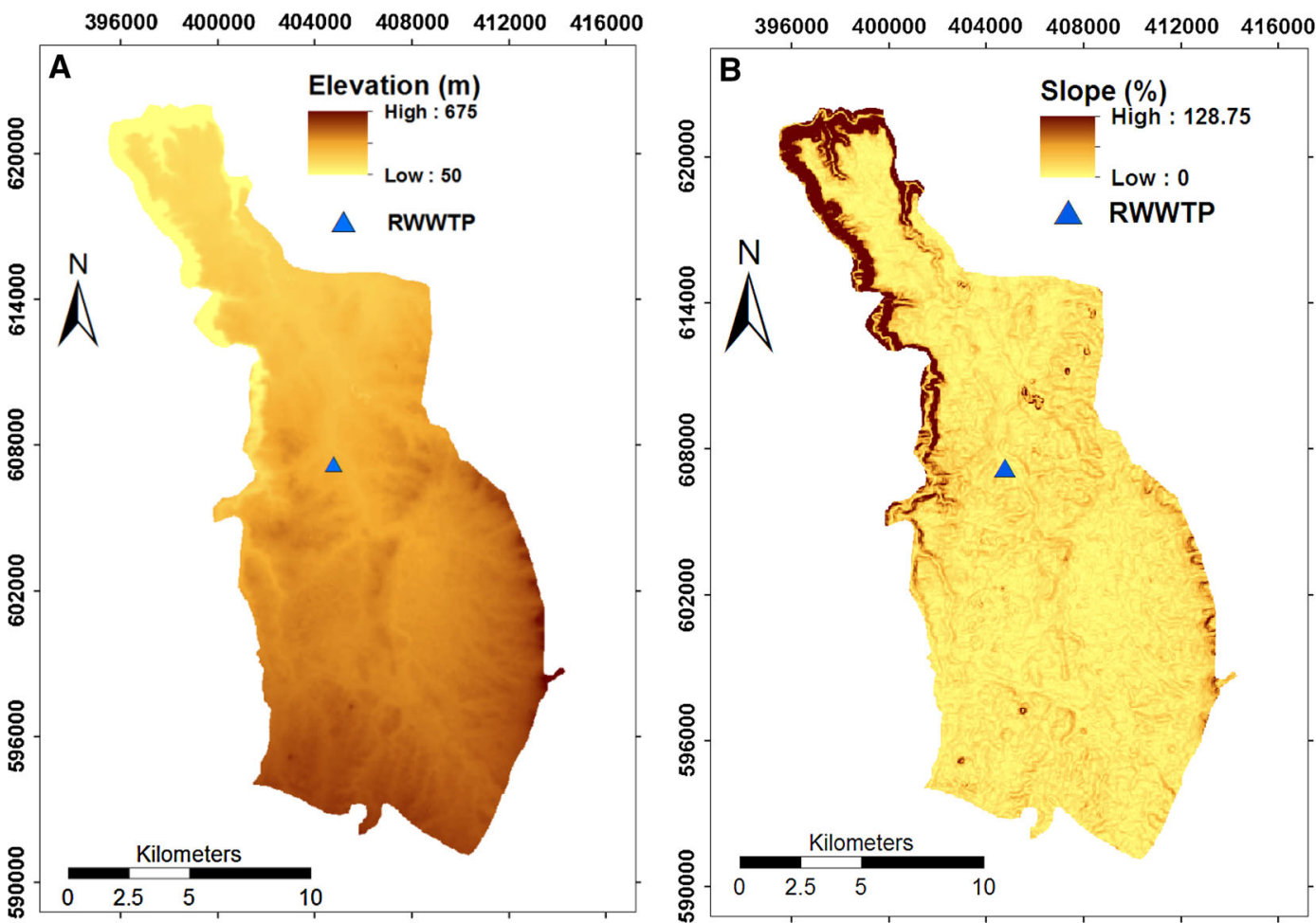

Fig. 5 Topography of the study area, DEM (a), and slope (b) in the study area 
Table 2 Recharge ratings and weightings for the study area. (Piscopo 2001, Al-Adamat et al. 2003)

\begin{tabular}{llllllcc}
\hline Slope $\%$ & Rating & Rainfall $(\mathrm{mm})$ & Rating & Soil Permeability & Rating & Net recharge & Rating \\
\hline$<2$ & 4 & $<500$ & 1 & Very slow & 1 & $11-13$ & 10 \\
$2-10$ & 3 & $500-700$ & 2 & Slow & Moderate & 3 & $9-11$ \\
$10-33$ & 2 & $700-850$ & 3 & Mod-high & 4 & $7-9$ & $5-7$ \\
$>33$ & 1 & $>850$ & & High & 5 & $3-5$ & 3
\end{tabular}

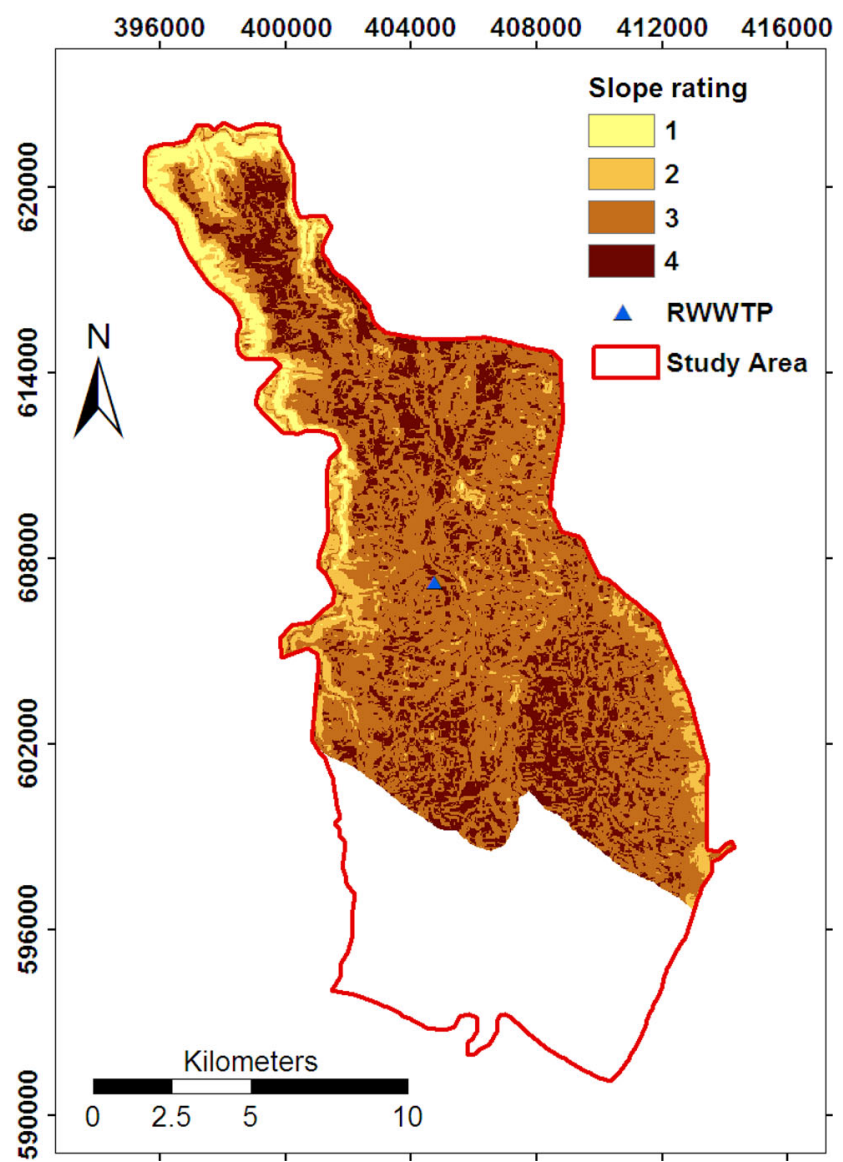

Fig. 6 Map of slope rating as factor in net recharge

properties: $\mathrm{pH}$, electrical conductivity (EC), and temperature. The collected samples were transported to the Water Analysis Lab of Yarmouk University and stored in the refrigerator until analysis to prevent deterioration and changes in water quality.

Spectrophotometer (Thermo, Evolution100) was used to determine the concentration of $\mathrm{NO}_{3}{ }^{-}$. Nitrate concentration was determined by adding $25 \mathrm{ml}$ from each sample in Erlenmeyer flask. Concentration $0.5 \mathrm{ml} 1 \mathrm{~N} \mathrm{HCl}$ was added to the sample and to the blank (distilled water). The absorbance was measured by the use of a spectrophotometer at $220 \mathrm{~nm}$ (APHA 1998). The concentration of $\mathrm{NO}_{3}{ }^{-}$ was calculated according to the following equation:

$$
\begin{aligned}
\mathrm{NO}_{3}^{-}(\mathrm{mg} / \mathrm{L})= & F_{\text {average }} \times(\text { Absorbance of Sample } \\
& - \text { Absorbance of Blank })
\end{aligned}
$$

where $F=42.52$, Absorbance of Blank $=0$

Results of analysis were mapped spatially using ArcGIS 10 to demonstrate the distribution of pollution indicators.

For quality assurance and quality control, a sample blank, which consists of reagent water and all reagents that are normally in contact with a sample during the entire analytical procedure, was used to minimize the errors that come from any of the prepared chemical reagents. Standard blank was also used to remove the errors during standards preparation; it consists of reagent water and all reagents that are normally in contact with standard preparation. Calibration curve was used to determine the expected ion concentration of a measured sample. This curve contains at least three concentrations of each standard ion solution. By plotting the absorbance of the desired certified standard with its concentration, the curve must have a linear relationship with regression value $\left(\mathrm{R}^{2}\right)$ greater than $99 \%$. In addition, duplicate analyses were used, i.e., measure each sample twice under the same conditions to remove any errors during chemical analysis and to remove any personal errors. The average of the results is taken and compared with standard calibration curve.

\section{Results and discussion}

The modified DRASTIC vulnerability index

ArcGIS 10 was used to query, manipulate, and analyze the data for the assessment of groundwater vulnerability map. All maps are projected in JTM (Jordan Transverse Mercator).

\section{Depth to groundwater}

The shallower the water table, the more vulnerable is the groundwater to contamination. Depth to groundwater in the study area varies from 7 to $132 \mathrm{~m}$ (Fig. 4a), and its rating varies between 1 and 7 (Fig. 4b). The most vulnerable 

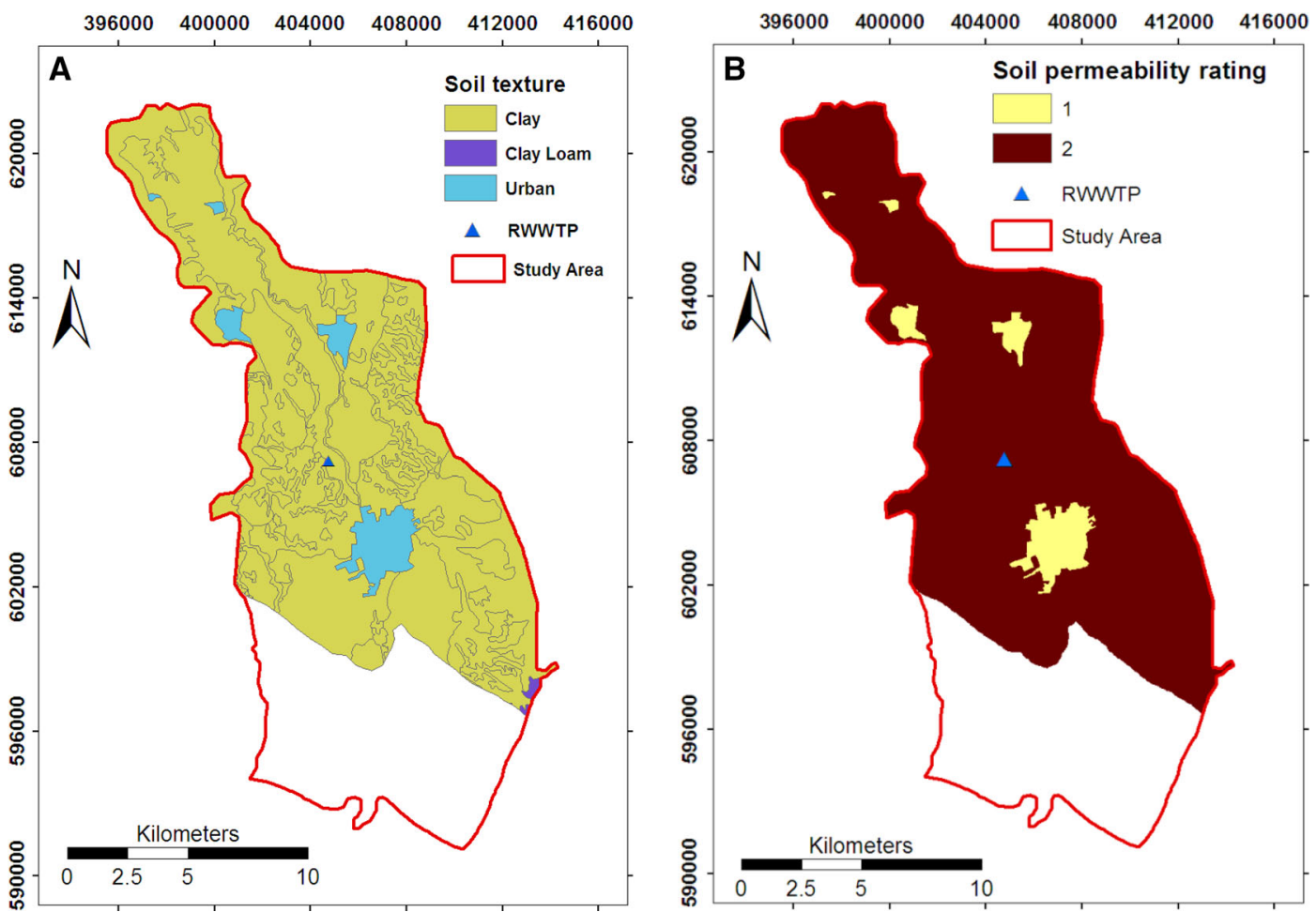

Fig. 7 Map of soil texture (a) and soil permeability rating (b) as a factor in net recharge in the study area
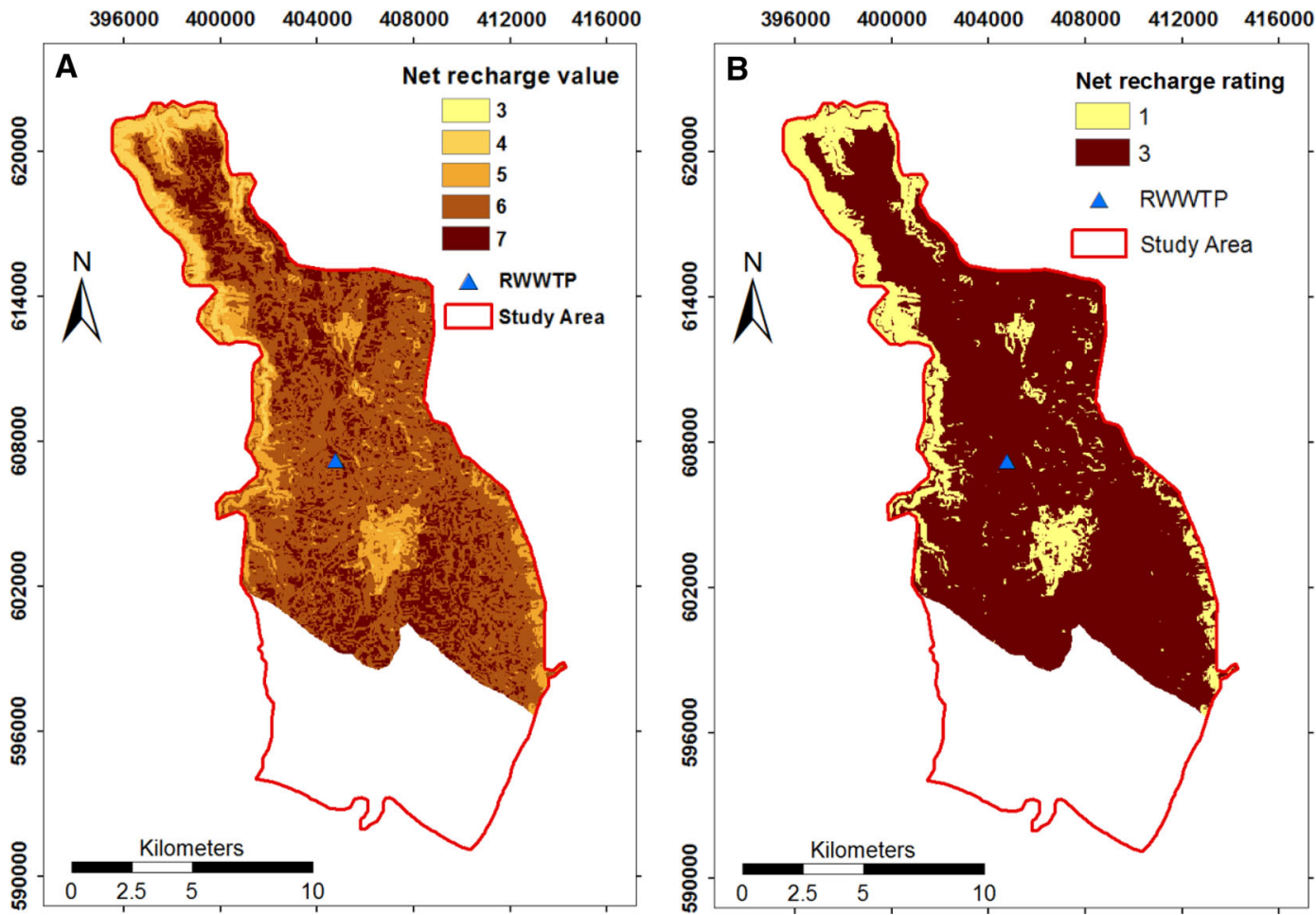

Fig. 8 Map of the net recharge value (a) and net recharge rating (b) in the study area 


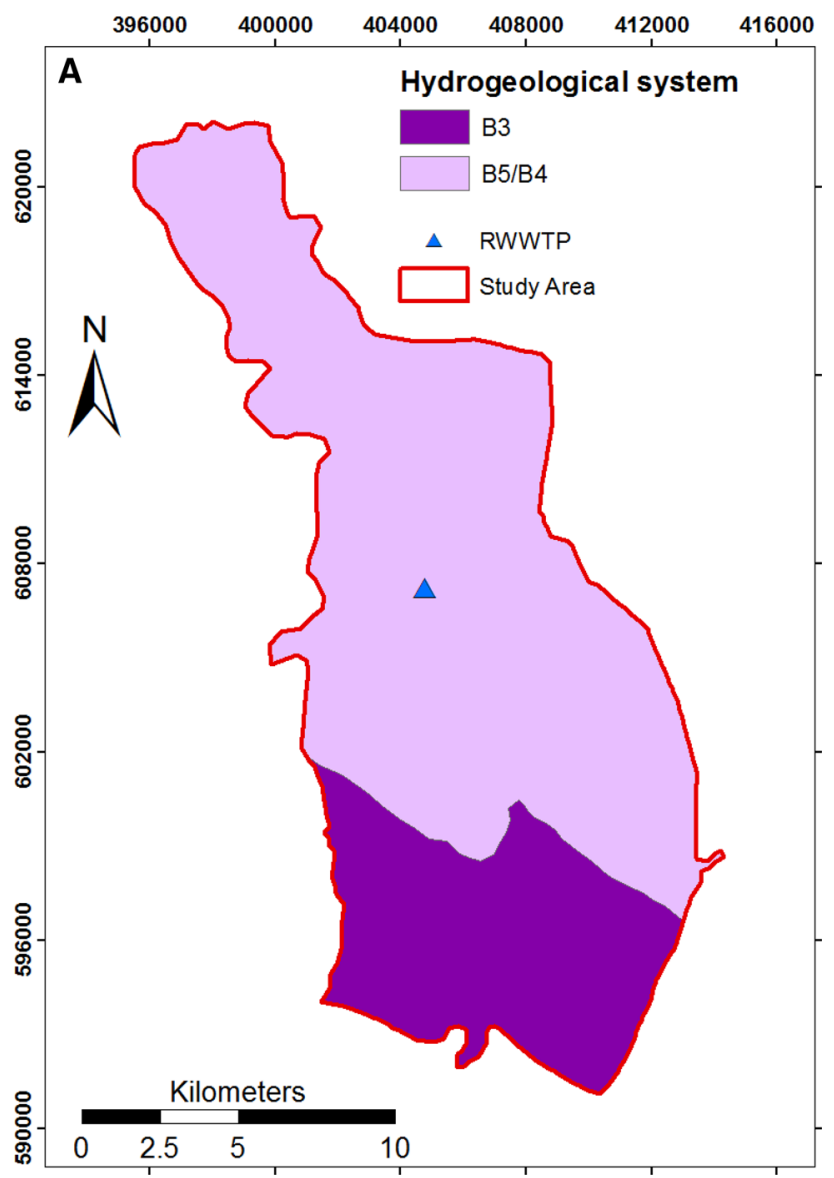

Fig. 9 Map of the aquifer media in the study area

groundwater was found in the central part of the study area surrounding the RWWTP.

\section{Net recharge}

Although net recharge dilutes the contaminant which enters the aquifer, it is the largest pathway for contaminant transport. Therefore, the amount of recharge is positively correlated with the vulnerability rating (Abdullahi 2009; Davis et al. 2002). Because there were no available data for net recharge in the study area, the following equation was used to calculate the net recharge value (Piscopo 2001):

Recharge value $=$ slope factor + rainfall factor $(\mathrm{mm})$ + soil permeability factor

The slope (\%) in the study area (Fig. 5b) was derived from the ASTER digital elevation model (DEM) (Fig. 5a). The soil permeability map was generated from soil texture map (Fig. 7a) of the Ministry of Agriculture. The soil permeability classification and rating were based on the USDA (1994). Since there are only two rainfall stations in the study area, we used the mean value $(256 \mathrm{~mm})$ only because surface creation from two points is not statistically

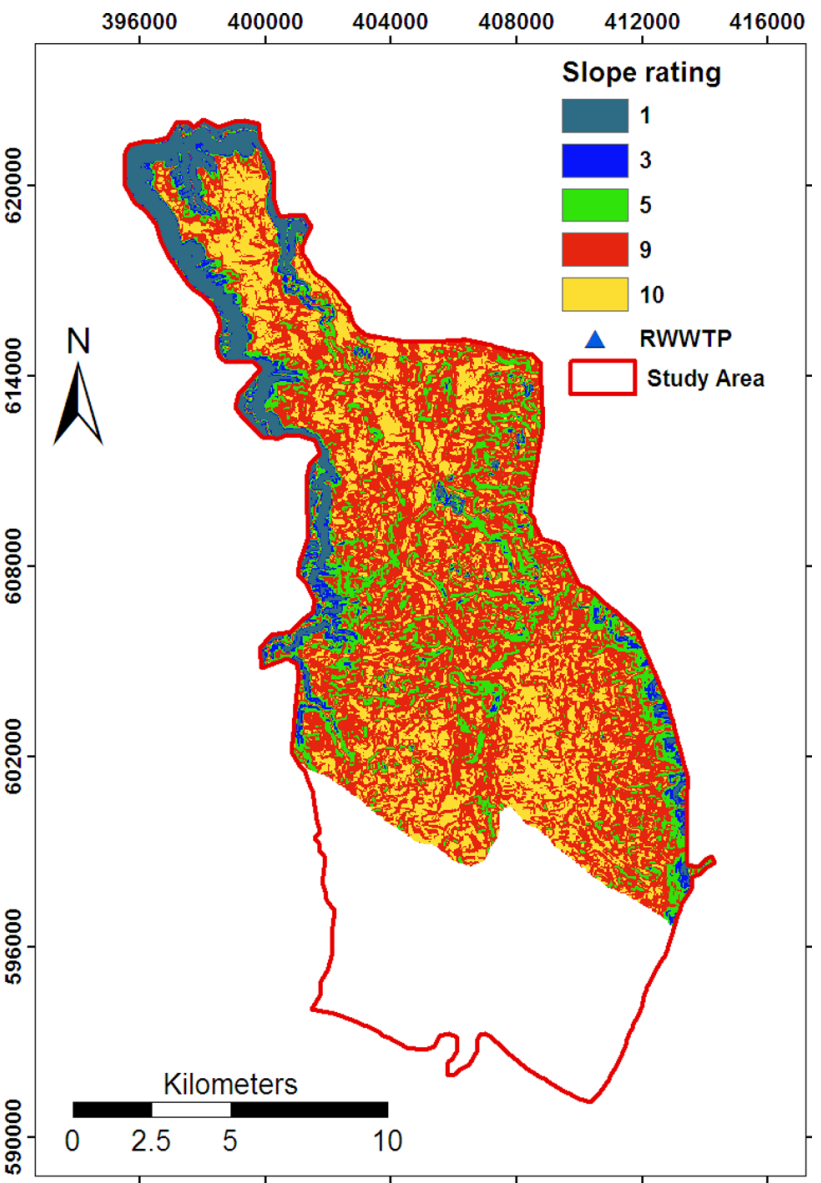

Fig. 10 Map of slope rating in the study area

correct. Therefore, a fixed rating value of 1 was used according to Table 2 (Piscopo 2001). In addition, the slope and soil maps were rated (Figs. 6, 7b) according to the criteria given in Table 2.

The net recharge map was generated by stacking the factors of the net recharge parameters, which was then reclassified (Fig. 8) according to the values given in Table 2. The DRASTIC ratings of the net recharge parameter in the study area have two values (1 and 3), which indicate low net recharge rate.

\section{Aquifer media}

The greater permeability of the aquifer has a greater pollution potential rating thus the more vulnerable is the groundwater to contamination. Limestone, permeable sandstone, and unconsolidated sand and gravel have a relatively high rating aquifer media, whereas shale and unfractured igneous and metamorphic rocks have a lower rating (Hearne et al. 1992). The aquifer (B4/B5), which dominates most of the study area, is assigned a rating value 4 , whereas the aquitard (B3) assigned a rating value 1 (Fig. 9). 


\section{Soil media}

The soil map (Fig. 7) of scale 1:50,000 was obtained from the Ministry of Agriculture (2005). The study area is dominated by clayey soil (rating value 2), with very small area occupied by clay loam (rating value 3 ). Urban areas assigned a rating value of 1 .

\section{Topography}

Slope map (Fig. 4b) was reclassified (Fig. 10) and rated in the range $1-10$, with rating values 9 and 10 dominating the study area.

\section{Impact of vadose zone}

The geologic map (Fig. 2) is rated to reflect the impact of vadose zone: 1, 3, 4, 7 and 9 (Fig. 11). Most of the study area is covered by rating 7 .

\section{Hydraulic conductivity}

Hydraulic conductivity map was generated based on the values (10 samples) taken from the open files of WAJ

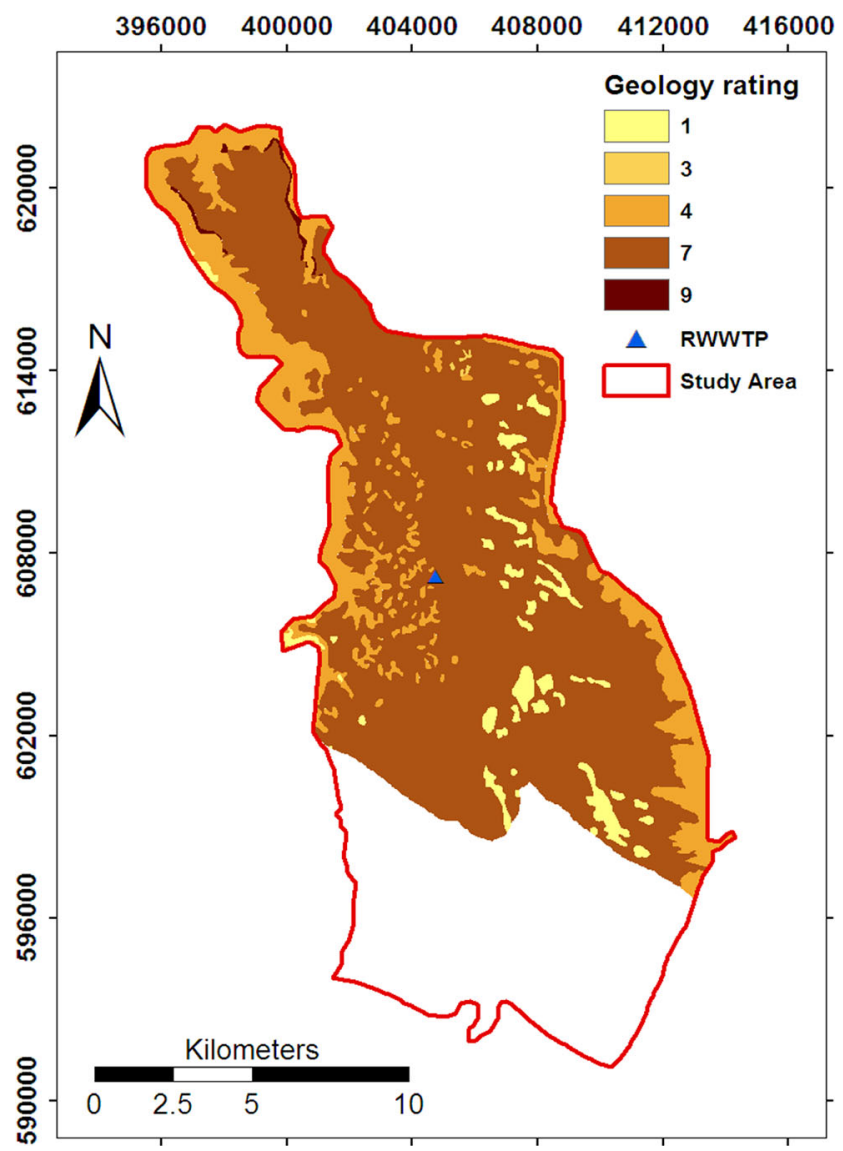

Fig. 11 Map of the impact of vadoze zone rating in the study area
(2006) (Fig. 12). The values of hydraulic conductivity ranged from $2.99 \mathrm{E}-6$ to $10 \mathrm{E}-5 \mathrm{~m} / \mathrm{s}$. DRASTIC ratings of the hydraulic conductivity in the study area were 1 and 2 only. The highly vulnerable groundwater according to hydraulic conductivity in the study area is found around and south east of the waste treatment plant.

\section{Lineaments}

The higher the lineament density means more vulnerable is the groundwater to contamination because lineaments are closely related to groundwater flow and contaminants migration (Mabee et al. 1994). Lineaments density was assigned a weight value of 5. Lineaments considered in the study area represent geological structures such as fractures and faults (Fig. 13a). A lineament density map was generated and rated into values 3 and 4 (Fig. 13b). The most vulnerable groundwater according to lineament density is found in the central parts of the study area.

\section{Land use/land cover}

The land use/land cover (LULC) in the study area comprises agriculture, rangeland, water, orchard, urban, and bareland (Fig. 14a). DRASTIC ratings of the LULC have the following values: 3,4,5,7 and 8 (Fig. 14b). Most of the

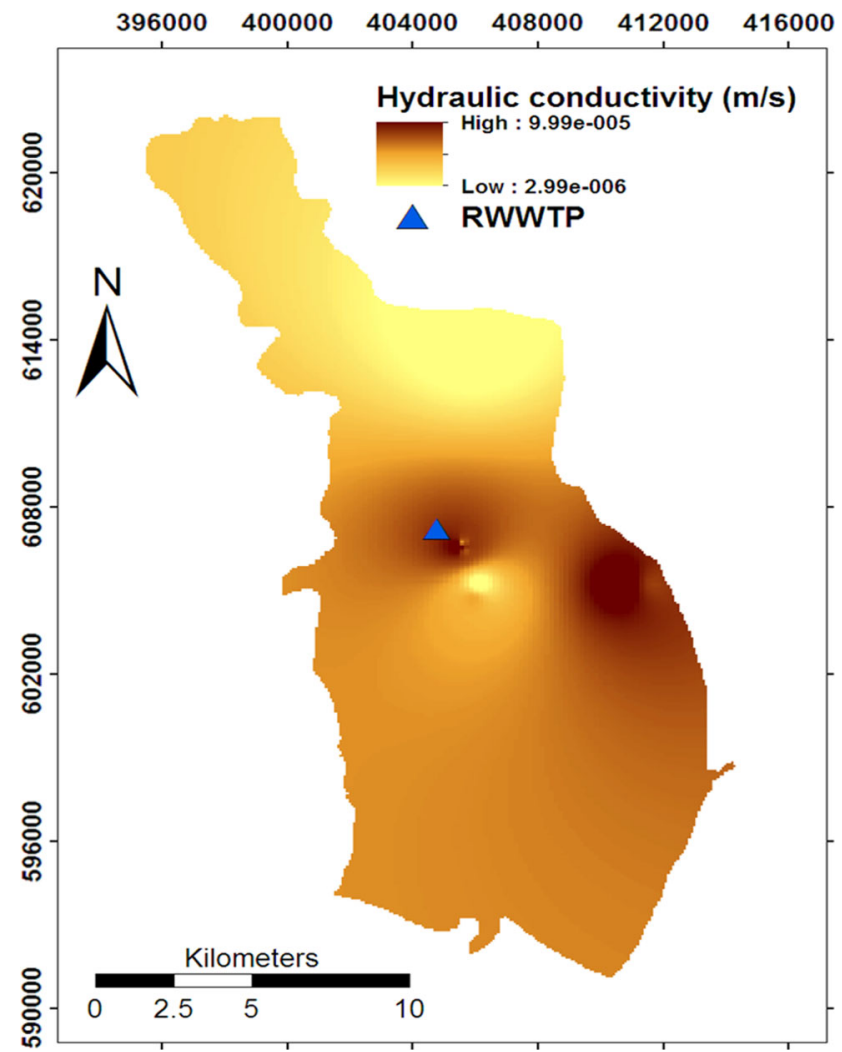

Fig. 12 Map of hydraulic conductivity $(\mathrm{m} / \mathrm{s})$ in the study area

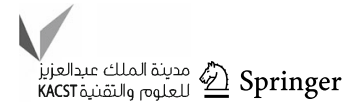



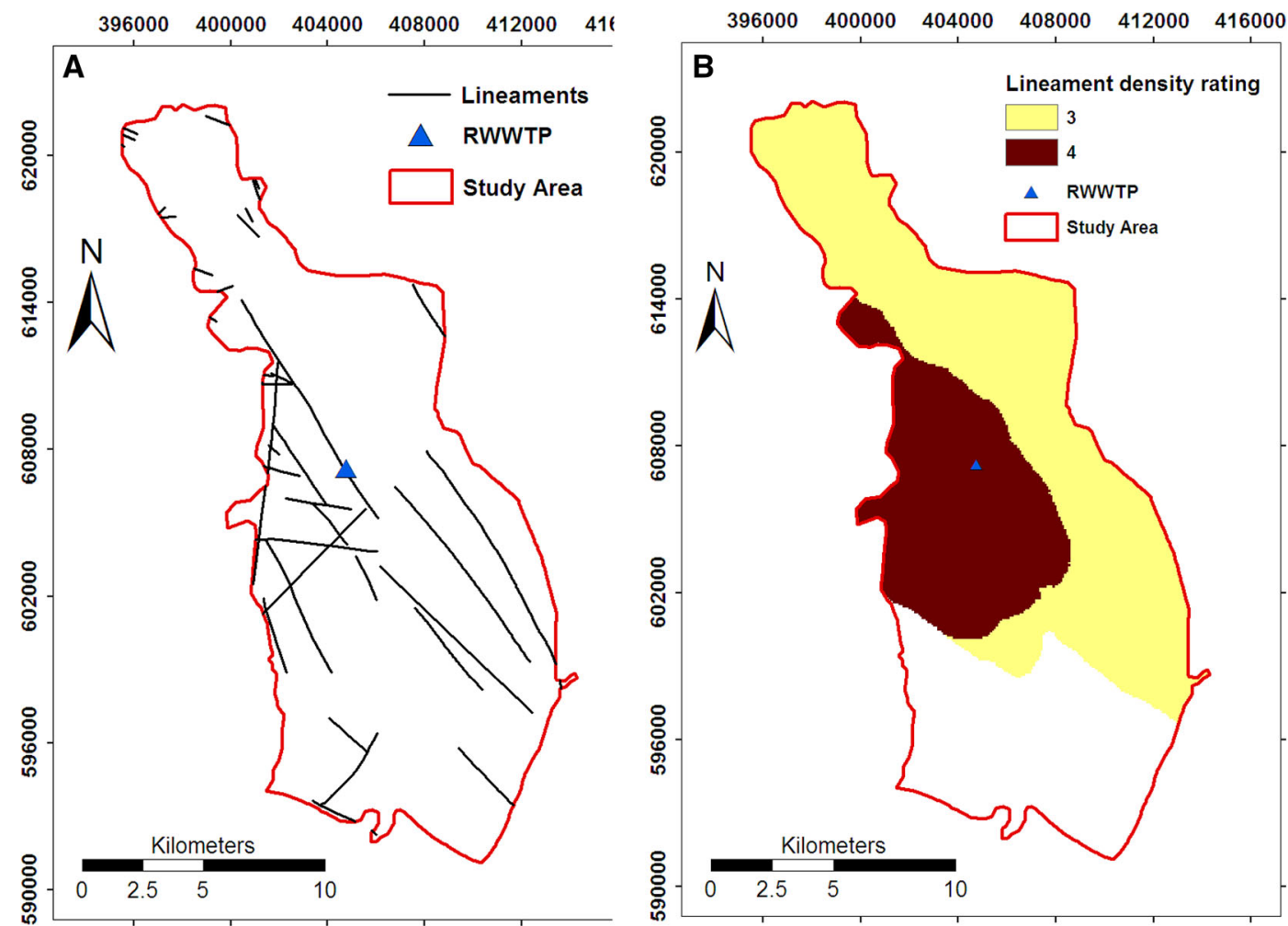

Fig. 13 Lineaments map (a) and lineament density rating (b) in the study area
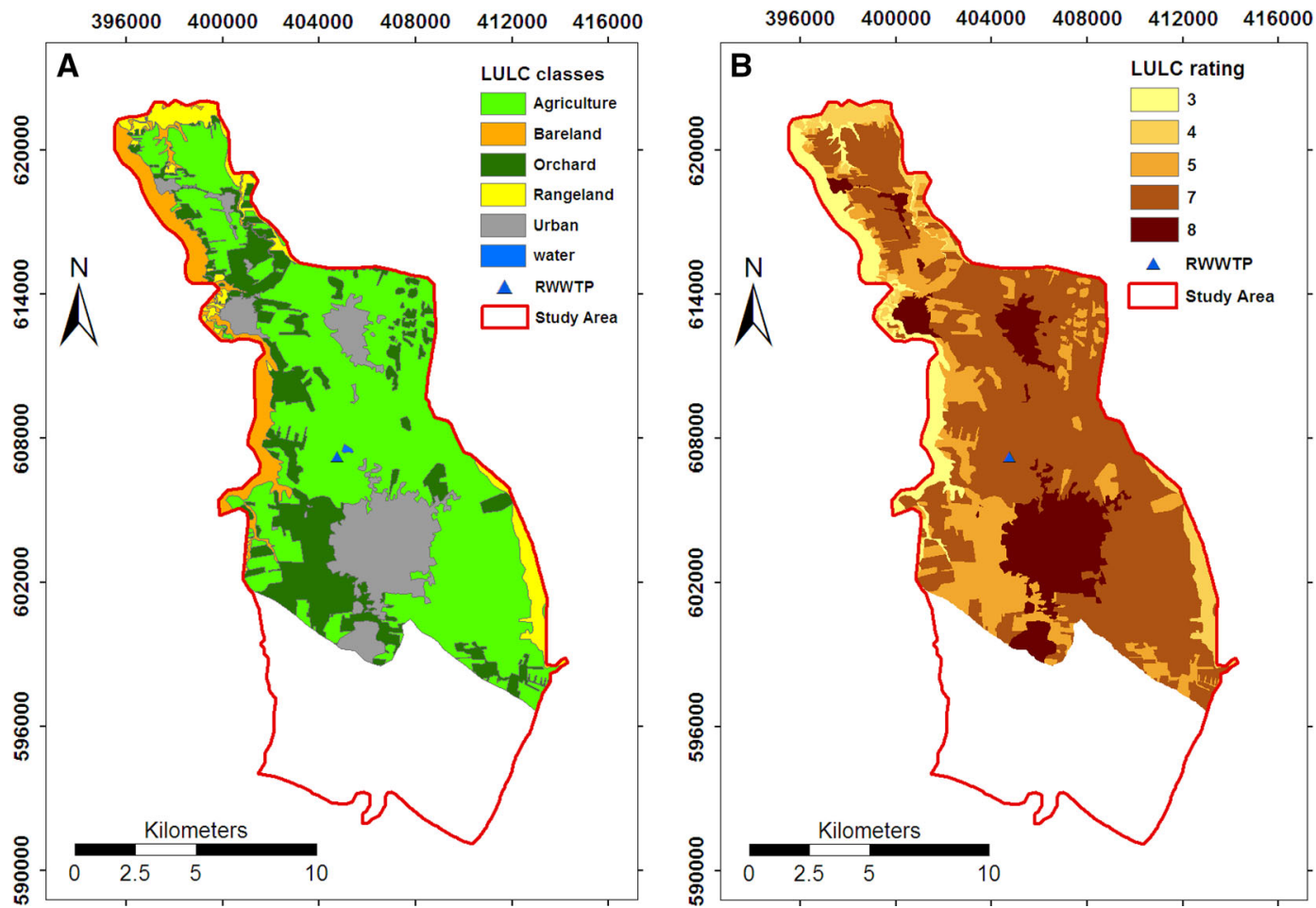

Fig. 14 Map of the major land use/land cover (a) in the study area and their ratings (b) 
Table 3 DRASTIC Index and vulnerability class (Aller et al. 1987)

\begin{tabular}{ll}
\hline DRASTIC index & Vulnerability class \\
\hline $1-100$ & Low \\
$101-140$ & Moderate \\
$140-200$ & High \\
$>200$ & Very high
\end{tabular}

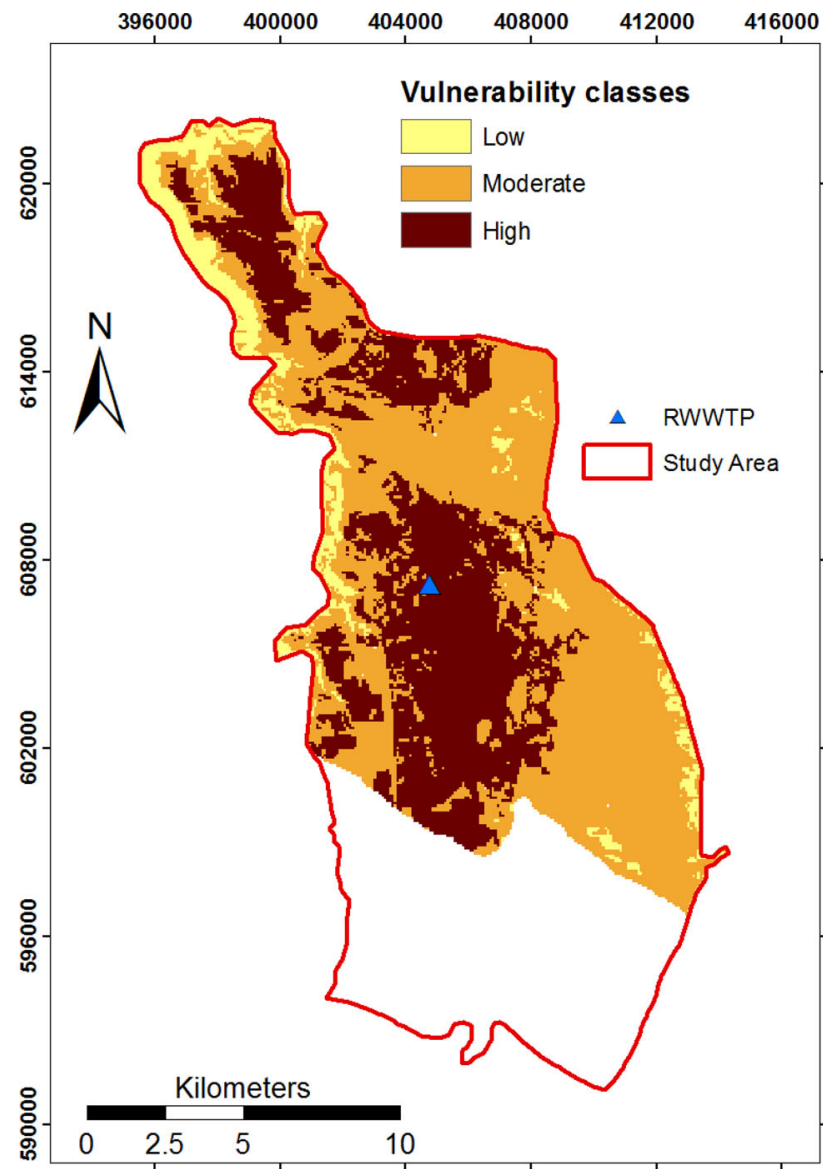

Fig. 15 The groundwater vulnerability map of the study area using the modified DRASTIC method

study area is covered by LULC rating 7, which represents agriculture.

\section{Groundwater vulnerability modeling}

The final modified DRASTIC vulnerability map was generated by overlying all the nine layers discussed earlier. The values of the DRASTIC index were classified according to the criteria given in Table 3 (Fig. 15). The vulnerability classes in the modified DRASTIC are low, moderate and high, which covered $9,54.5$, and $36.5 \%$ of the study area, respectively.

As it is shown in Fig. 15a, the RWWTP is found within the high vulnerability class. This is due to the fact that

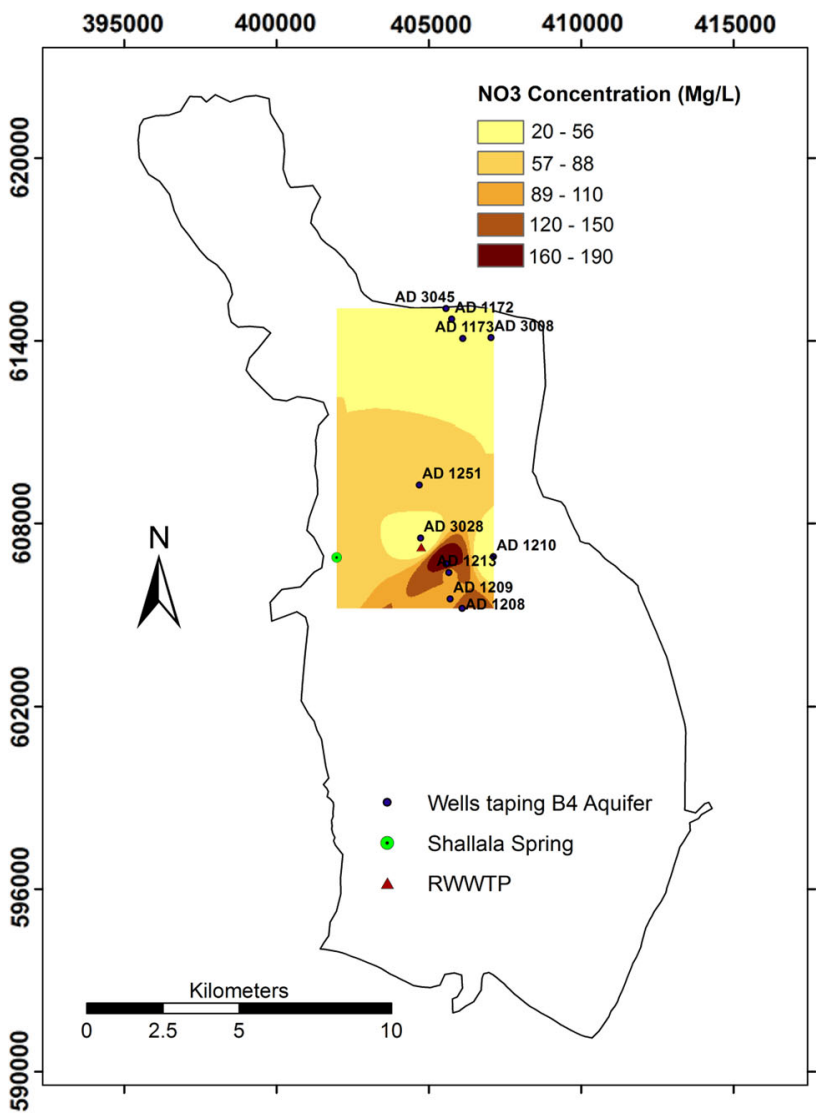

Fig. 16 Spatial distribution of the averages of the nitrate concentration for B4

depth to groundwater is shallow, with high net recharge value, high aquifer permeability, low slope, soil texture, high hydraulic conductivity, and high lineament density and land use (agriculture).

Sensitivity analysis

The highest variation index ( $27 \%$ ) is due to the removal of the LULC parameter from the model. This could mainly be attributed to the high theoretical weight assigned to this parameter (5). Hydraulic conductivity is the parameter that has the lowest effect on the variation in the final vulnerability (4\%). The vulnerability index also seems to be sensitive to the removal of the impact of vadose zone and lineament density (variation index $=20$ and $13.5 \%$, respectively).

The single-parameter sensitivity analysis showed that the LULC parameter tends to be the most effective parameter in the vulnerability assessment (mean effective $w t \%$ is 23.2) in agreement with the result from map removal sensitivity analysis. Its effective weight exceeds the theoretical weight $(15.2 \%)$. The impact of vadose zone also shows high effective weight (18.7\%) that exceeds the theoretical weights $(15.2 \%)$. The rest of the parameters, 
Fig. 17 Temporal variation in NO3-concentration for well no.AD1251 (a) and well no.AD1173 (b)
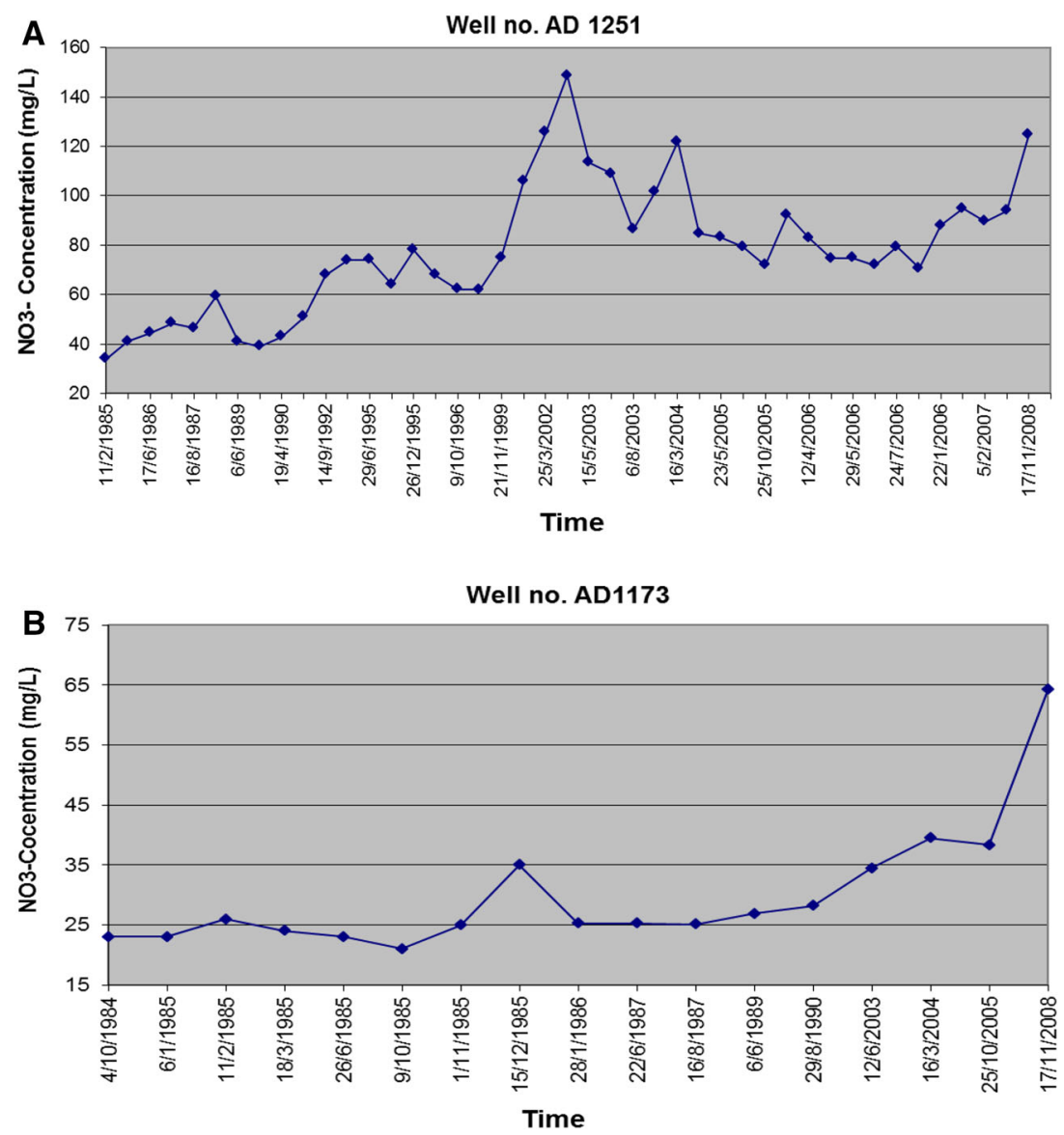

excluding topography have lower effective weights as compared to the theoretical weights. The significance of impact of vadose zone and LULC parameters highlights the importance of obtaining accurate, detailed, and representative information about these factors.

\section{Model validation}

\section{Spatial concentrations of nitrate}

Twelve samples of groundwater wells were sampled and analyzed for nitrate. Nitrate concentration in B4 aquifer was in the range of $20-193 \mathrm{mg} / \mathrm{L}$ with an average of $65.5 \mathrm{mg} / \mathrm{L}$. The lowest value was recorded for well no. AD3028 and the highest value was recorded for well no. AD1296. Sixty-nine and $54 \%$ of the B4 groundwater samples exceed the permissible limit of WHO (1993) and Jordanian (2001) standards of nitrate, respectively. Figure 16 shows that the highest concentration of $\mathrm{NO}_{3}{ }^{-}$for B4 aquifer was found toward the southeast of RWWTP.

Nitrate concentrations in the range $20-50 \mathrm{mg} / \mathrm{L}$ indicate the influence of human activities (Spalding and Exner 1993), whereas nitrate concentrations $>50 \mathrm{mg} / \mathrm{L}$ are higher than the maximum acceptable concentration for drinking water (WHO 1993). It is found that 5 wells $(83.5 \%)$ of those having high nitrate concentration $(>50 \mathrm{mg} / \mathrm{L})$ are located in the highly vulnerability zone; and only the Shallala Spring is located in the moderate zone. Also, five of the wells $(83.5 \%)$ of those having a nitrate concentration between 20 and $50 \mathrm{mg} / \mathrm{L}$ are located in the moderate vulnerability zone. Only well no. AD3028 is found in the high vulnerability zone. These results show a very good match between nitrate concentrations level and the groundwater vulnerability model.

Nitrate concentration in the study area was correlated with depth to water table $(r=-0.51)$. High concentration of nitrate is found in the area surrounding RWWTP, where depth to water table is $<20 \mathrm{~m}$ below ground surface; this increases aquifer's vulnerability to contamination. Several studies showed a negative correlation between depth to groundwater and nitrate concentration (Changyuan et al. 2004; Enwright and Hudak 2009). A strong correlation $(r=0.70)$ exists between lineaments density and nitrate concentration. The pollution plume decreases away from the plant, towards the north, south, and east. A significant correlation exists between nitrate concentration and distance from the treatment plant $(r=-0.75)$. 


\section{Temporal variation of nitrate}

Nitrate concentration for well no. AD1251 (1985-2008) has increased from $34 \mathrm{mg} / \mathrm{L}$ in 1985 to more than $145 \mathrm{mg} /$ L in 2002 (Fig. 17a). Starting 2003, the nitrate concentrations showed a clear decreasing trend, which is attributed to the upgrading of RWWTP from stabilization ponds to activated sludge treatment process.

Well no. AD1173 (1984-2005) showed a clear increase in nitrate concentration from an average of $25 \mathrm{mg} / \mathrm{L}$ before the existence of the treatment plant to $35 \mathrm{mg} / \mathrm{L}$ afterwards (Fig. 17b). However, the upgrading of the treatment plant did not reflect on the nitrate concentrations most probably because of the far distance between the plant and the groundwater well and topography. Statistical analysis by Obeidat et al. (2013) indicated significant differences between nitrate concentration before and after the construction of RWWTP.

\section{Conclusions}

The modified DRASTIC model developed a more accurate vulnerability map by adding the two parameters: land use and lineaments. Model validation proved good agreement between nitrate and the final vulnerability map. However, calibration of the DRASTIC model will depict groundwater vulnerability with higher accuracy in the view of model validation. Sensitivity analysis showed that the parameters LULC and the impact of vadose zone are most effective in vulnerability assessment. In B4 aquifer, there are 10 wells occurred in the zone of high vulnerability, and 1 well occurred in the zone of moderate vulnerability.

About 69 and $54 \%$ of the B4 groundwater samples $\mathrm{NO}_{3}{ }^{-}$concentrations exceeded the permissible limit, the WHO (1993) and the Jordanian (2001) standards, respectively. Temporal data indicated the increase of nitrated concentrations due to the establishment of the RWWTP.

Acknowledgments Thanks are due to the Deanship of Scientific Research and Graduate Studies at Yarmouk University for providing the financial support to implement this work.

Open Access This article is distributed under the terms of the Creative Commons Attribution License which permits any use, distribution, and reproduction in any medium, provided the original author(s) and the source are credited.

\section{References}

Abdullahi U (2009) Evaluation of models for assessing groundwater vulnerability to pollution in Nigeria. Bayero J Pure Appl Sci 2:138-142
Al-Adamat R, Foster I, Baban S (2003) Groundwater vulnerability and risk mapping for the Basaltic aquifer of the Azraq basin of Jordan using GIS, remote sensing and DRASTIC. Appl Geogr 23:303-324

Al-Hanbali A, Kondoh A (2008) Groundwater vulnerability assessment and evaluation of human activity impact (HAI) within the Dead Sea groundwater basin Jordan. Hydrogeol J 16(3):499-510

Aller L, Bennett T, Lehr J, Petty R, Hackett G (1987) DRASTIC: a standardized system for evaluating groundwater pollution potential using hydrogeologic settings: U.S. environmental protection agency report 600/2- 87/035, p 622

Awawdeh MM, Jaradat RA (2010) Evaluation of aquifers vulnerability to contamination in the Yarmouk River basin, Jordan, based on DRASTIC method. Arab J Geosci 3(3):273-282

Babiker I, Mohammed M, Hiyama T, Kato K (2005) A GIS-based DRASTIC model for assessing aquifer vulnerability in kakmigahara heights, Gifu Prefecture, central Japan. Sci Total Environ 345:127-140

Baker L (1992) Introduction to non-point source pollution in the United States and prospects for wetland use. Ecol Eng 1:1-26

Burkart MR, Feher J (1996) Regional estimation of ground water vulnerability to nonpoint sources of agricultural chemicals. Water Sci Technol 33(4-5):241-247

Changyuan T, Jianyao C, Njun S (2004) Long-term effect of wastewater irrigation onnitrate in groundwater in the North China Plain. In: Steenvoorden J, Endreny T (eds) Wastewater reuse and groundwater quality. Proceedings symposium HS04: IAHS Publications, Red Book Series, 285, pp 34-40

Connell L, Daele G (2003) A quantitative approach to aquifer vulnerability mapping. J Hydrol 276:71-88

Davis A, Long A, Wireman M (2002) A sensitivity method for carbonate aquifers in karst terrain. Environ Geol 42:65-72

Enwright N, Hudak P (2009) Spatial distribution of nitrate and related factors in the High Plains Aquifer, Texas. Environ Geol 58:1541-1548

Evans B, Mayers W (1990) A GIS-based approach to evaluating regional groundwater pollution potential with DRASTIC. J Soil Water Conserv 45:242-245

Ford M, Tellam J (1994) Source, type and extent of inorganic contamination within the Birmingham urban aquifer system, UK. J Hydrol 156:101-135

Fortin M, Thomson K, Edwards G (1997) The role of error propagation for integrating multisource data within spatial models: the case of the DRASTIC groundwater vulnerability model. Earth Surface Remote Sensing. London: Procedure SPIE Conference, pp 358-361

Fritch T, McKnight C, Yelderman J, Arnold J (2000) An aquifer vulnerability assessment of the paluxy aquifer, central Texas, USA, using GIS and a modified DRASTIC approach. Environ Manag 25:337-345

Hadadin N, Qaqish M, Akawwi E, Bdour A (2010) Water shortage in Jordan-sustainable solutions. Desalination 250:197-202

Hasiniaina F, Guoyi L, Zhou J (2010) Regional assessment of groundwater vulnerability in Tamtsag basin, Mongolia using DRASTIC model. J Am Sci 6(11):69

Hearne G, Wireman M, Campbell A, Turner S, Ingersoll G (1992) Vulnerability of the uppermost ground water to contamination in the greater Denver area. US Geological Survey, WaterResources Investigations Report 92-4143

Huan H, Wang J, Teng Y (2012) Assessment and validation of groundwater vulnerability to nitrate based on a modified DRASTIC model: a case study in Jilin City of northeast China. Sci Total Environ 440:14-23

Hubbard R, Sheridan J (1994) Nitrates in groundwater in the southeastern USA. In: Adriano D, Iskadar A, Murarka I (eds)

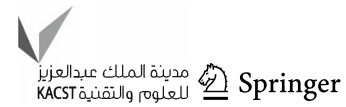


Contamination of groundwater. Northwood, United Kingdom, Science Reviews, p 45-303

Jordanian Standards JS 286 (2001) Water-drinking water, 4th edn, Department of Standards and Specifications, Amman, The Hashemite Kingdom of Jordan

Knox R, Sabatini D, Canter L (1993) Subsurface transport and fate processes. Lewis Publishers, USA

Lake IR (2003) Evaluating factors influencing groundwater vulnerability to nitrate pollution: developing the potential of GIS. J Environ Manag 328(68):315-328

Lerner D, Yang Y, Barrett M, Tellam J (1999) Loading of nonagricultural nitrogen in urban groundwater. In: Ellis, JB (ed), Impacts of urban growth on surface and groundwater quality, IAHS publ. No. 259. IAHS Press, p 117-123

Lodwick W, Monson W, Svoboda L (1990) Attribute error and sensitivity analysis of map operations in geographical information system. Int J Geogr Inf Syst 4:13-28

Mabee S, Hardcastle K, Wise D (1994) A method of collecting and analyzing lineaments for regional-scale fractured-bedrock aquifer studies. Groundwater 32(6):884-894

MacQuarrie K, Sudicky E, Roberston W (2001) Numerical simulation of a fine-grained denitrification layer for removing septic system nitrate from shallow groundwater. J Hydrol 52:29-55

Margane A, Hobler M, Subah A (1999) Mapping of groundwater vulnerability and hazards to groundwater in the Irbid Area, N Jordan. Z Angew Geol 45(4):175-187

Mclay CD, Dragten R, Sparling G, Selvarajah N (2001) Predicting groundwater nitrate concentrations in a region of mixed agricultural land use: a comparison of three approaches. Environ Pollut 115(2):191-204

Mohsen M (2007) Water strategies and potential of desalination in Jordan. Desalination 203:27-46

Napolitano P, Fabbri A (1996) Single-parameter sensitivity analysis for aquifer vulnerability assessment using DRASTIC and SINTACS. Hydrol Water Resour Manag 235:559-566

Natural Resources Authority (1997) Geological Map of Irbid scale 1:50,000, sheet no. 15. Royal Jordanian Geographic Center, Amman

Navarro A, Carbonell M (2007) Evaluation of groundwater contamination beneath an urban environment: the Besòs river basin (Barcelona, Spain). J Environ Manag 85:259-269

Navulur K, Engel B (1998) Groundwater vulnerability assessment to non-point source nitrate pollution on a regional scale using GIS. Trans Am Soc Agric Eng 41:1671-1678

Nawafleh A, Awawdeh M, Salameh E (2011) Assessment of groundwater vulnerability to contamination in Irbid Governorate, North Jordan. DIRASAT 38(2)
Obeidat M, Awawdeh M, Al-Mughaid H (2013) Impact of a domestic wastewater plant on groundwater pollution, north Jordan. The Revista Mexicana de Ciencias Geológicas 30:371-384

Piscopo G (2001) Groundwater vulnerability map, explanatory notes, Castlereagh Catchment, NSW. Department of Land and Water Conservation, Australia, http://www.dlwc.nsw.gov.au/care/ water/groundwater/reports/pdfs/castlereagh_map_notes.pdf. Accessed 20 Nov 2012

Postma D, Boesen C, Kristiansen H, Larsen F (1991) Nitrate reduction in an unconfined sandy aquifer: water chemistry, reduction processes and geochemical modeling. Water Resour Res 27:45-202

Rundquist DC, Peters AJ, Di L, Rodekohr DA, Ehrman RL, Murray G (1991) Statewide groundwater vulnerability assessment in Nebraska using the DRASTIC/GIS model. Geocarto Int 6:51-58

Rupert MG (2001) Calibration of the DRASTIC ground water vulnerability mapping method. Ground Water 39(4):625-630

Secunda S, Collin M, Melloul A (1998) Groundwater vulnerability assessment using a composite model combining DRASTIC with extensive agricultural land use. Environ Manag 54:39-57

Seiler R (2005) Combined use of $15 \mathrm{~N}$ and $18 \mathrm{O}$ of nitrate and $11 \mathrm{~B}$ to evaluate nitrate contamination in groundwater. Appl Geochem 20:1626-1636

Spalding R, Exner M (1993) Occurrence of nitrate in groundwater-a review. J Environ Qual 22:392-402

Stigter T, Almeida P, Carvalho D, Ribeiro L (2006) Evaluation of an intrinsic and a specific vulnerability assessment method in comparison on a regional scale. Hydrogeol J 14(3):79-99

United Nations (2006) Common Country Assessment: Jordan

United States Environmental Protection Agency (US EPA) (1994) Handbook: Groundwater and Wellhead Protection. US EPA Report No. EPA/625/R-94/001, Washington, DC, p 239

Vrba J, Zaporozec A (1994) Guidebook on mapping groundwater vulnerability-AH International Contributions to Hydrogeology 16, Hannover/FRG (Heise Publ.) p 131

Wakida T, Lerner D (2005) Non-agricultural sources of groundwater nitrate: a review and case study. Water Res 39:3-16

Wardam B (2004) More politics then water: water rights in Jordan. IUCN regional water program in west Asia and North Africa, Jordan. Global Issue paper No. 11

WHO (World Health Organization) (1993) Guidelines for drinking water quality, vol 1, Recommendations, 2nd edn, WHO, Geneva

Zwahlen F (ed) (2004) Vulnerability and risk mapping for the protection of carbonate (karst) aquifers. Final report (COST Action 620). European Commission, p 297 